\title{
Exploiting Scanning Behavior for Predators Can Reduce Rice Damage Caused by Birds
}

\author{
Takeshi Honda \\ Yamanashi Prefecture Agricultural Research Center, Shimoimai 1100, Kai, Yamanashi 400-0105, Japan \\ Correspondence should be addressed to Takeshi Honda; honda-yvj@pref.yamanashi.lg.jp
}

Received 4 August 2015; Accepted 30 August 2015

Academic Editor: Eugene S. Morton

Copyright ( 2015 Takeshi Honda. This is an open access article distributed under the Creative Commons Attribution License, which permits unrestricted use, distribution, and reproduction in any medium, provided the original work is properly cited.

\begin{abstract}
Rice is often damaged by birds, especially sparrows, in Asia. Bird nets are sometimes used as countermeasures; however this approach is expensive and labor intensive. For this reason, farmers generally eschew bird nets, even though no alternative countermeasures are available. This study focused on exploiting the bird behavior of scanning for predators to reduce crop damage. When birds forage for seeds on the ground they often stop pecking and briefly raise their heads, apparently to scan for predators. Low visibility habitats increase scanning behavior and increased scanning behavior reduces habitat quality from the bird's perspective; therefore, this study tested the relationship between rice damage rate and visibility at the periphery of rice fields, where tree sparrows rest after feeding. Overall, low visibility reduced damage to rice. Because visibility was mainly affected by weeds, weed management techniques contribute to crop damage management. To reduce damage, weeding can be decreased; therefore, this technique is costand labor-efficient.
\end{abstract}

\section{Introduction}

A feeding animal must not only concentrate on food consumption per se but must simultaneously be vigilant for potential predators $[1,2]$. When birds forage for seeds on the ground they often stop pecking and briefly raise their heads, apparently to scan for predators. Scanning for predators and pecking for food are assumed to be incompatible activities. Many factors can potentially affect scanning behavior, for example, flock size [3-5], visibility [6], and distance from cover [7]. Large flock size, good visibility, and short distance to protective cover all decrease the scanning rate [5-7]. In particular, among species that rely on detecting predators by sight, increased visual obstruction has been shown to increase vigilance in a variety of species from many taxa [6]. This suggests that foraging in patches with reduced visibility will impose the dual costs of reduced foraging efficiency and increased predation risk. In general, limited visibility decreases the pecking rate by $30 \%$ [6]. Therefore, predation risk can alter habitat choice, wherein low visibility habitat would be avoided [6].

Rice is often damaged by tree sparrows (Passer montanus) in Japan [8]. Can we exploit bird scanning behavior to prevent this damage? If visibility at the peripheries of paddy fields is high, scanning frequencies tend to be lower [6], which is convenient for birds. If the peripheral visibility of a paddy field is reduced by visual obstructions (i.e., weeds), tree sparrows, which often rest on the peripheries of paddy fields (i.e., out of paddy fields) after feeding [9], are unable to rest. Therefore, weeding techniques should affect the scanning rate and consequently may represent an agronomic approach to managing tree sparrow damage. This study focused on the peripheries of paddy fields (i.e., the resting places); predation risk in these resting places will affect the selection of feeding habitats.

Although several techniques are used to deter birds, such as sonic, visual, and olfactory deterrents, as well as chemical repellents, almost all methods are impractical because they result in habituation or have limited effects [10]. For example, distress calls are effective against some species but can result in habituation [11, 12]. Among visual deterrents, lasers are effective only against certain species $[13,14]$. Although olfactory stimuli have not been thoroughly examined, naphthalene was found to be ineffective [15]. Chemical repellents are effective on some levels but can leave residues that make crops unsuitable for human consumption and are thus impractical 
[16]. The only method that has not resulted in habituation is bird netting [17]. Bird nets are effective but impractical because of the high costs and intensive labor associated with their installation and upkeep $[17,18]$.

Thus, there are currently no truly effective methods for preventing sparrow damage. In this paper, I explore an agronomic approach to reducing bird feeding damage as a potential solution. Paddy fields need weed management only when most vulnerable to birds, and the weeds themselves do not have to be cut, so my proposed approach is not labor intensive. Visibility was affected mainly by weeds; tall weeds are visual obstructions, while cropped weeds make tree sparrows less vigilant. Overall, my aim is to reveal the relationship between the visibility of resting sites in paddy fields and damage caused by tree sparrows.

\section{Materials and Methods}

This study was conducted in Yamanashi Prefecture, Central Japan. In this region, paddy fields are mainly located in lowlands (e.g., Kofu city). In Kofu (272 m a.s.l.), in the center of the study area, the mean annual temperature is $14.3^{\circ} \mathrm{C}$, the mean annual precipitation is $1109 \mathrm{~mm}$, and the maximum snow depth is $140 \mathrm{~mm}$.

From September 2 to September 9, 2014, I tested the relationship between canopy openness and rice damage caused by tree sparrows. This investigation period coincided with the time when most rice crop damage occurs. Canopy openness was measured using an $180^{\circ}$ fisheye lens (Canon D10 camera and DIGITAL KING $180^{\circ}$ Fisheye L-size T03L). Hemispherical photographs were taken at the point of highest canopy openness within $1 \mathrm{~m}$ of the paddy field (i.e., out of paddy field). Photographs were taken from the ground and the thickness of the compact digital camera was thin enough to simulate the position of eye ball of sparrows. Canopy openness was assessed along the four outer edges of the paddy fields. After taking pictures, canopy openness was calculated using CANOPON software. My aim was to detect reduced visibility due to weeds; therefore, I surveyed only tree-free areas. Damage was assessed along the four outer edges of the paddy fields by examining 20 rice plants on each side and determining the damage rate. In general, damage is most serious at the outer edge of paddy fields [19]. Because this method of data collection may result in autocorrelation, I used generalized linear mixed models with binomial distributions during analysis. Each paddy field had a different ID number and a different intercept (i.e., random intercept). This method handles not only autocorrelation but also unobserved effects that might cause damage. Statistical analysis was conducted using R 2.14.2 software [20] and the glmmML library.

\section{Results and Discussion}

Overall, I assessed 28 paddy fields randomly. The damage rate ranged from $0 \%$ to $80 \%$ of rice plants, and canopy openness ranged from $33.1 \%$ to $96.2 \%$. The relationship between damage rate and canopy openness was shown (Figure 1). Damage

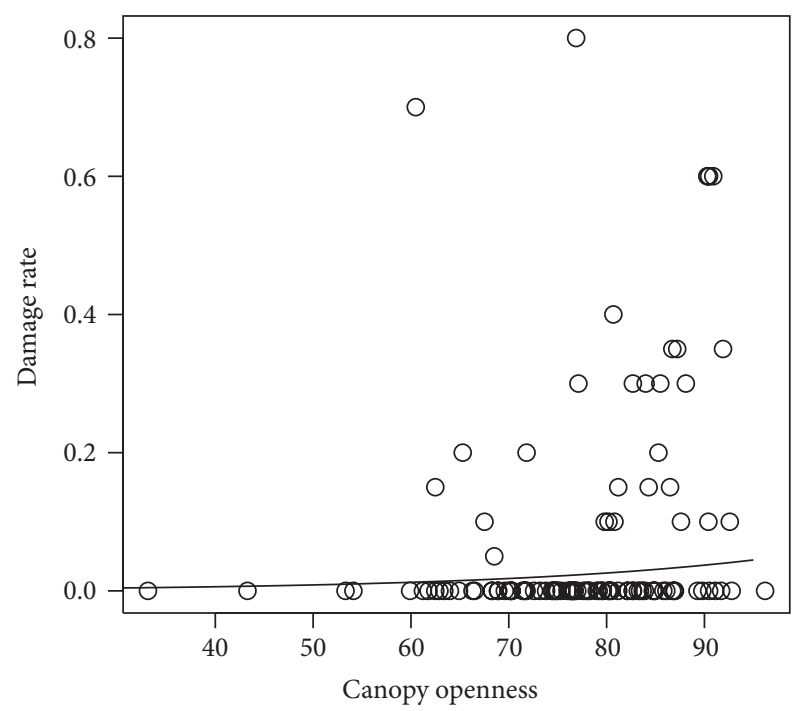

FIGURE 1: Relationship between canopy openness of resting sites in paddy fields and rate of damage to rice plants. Canopy openness (\%) was calculated using a fisheye-lens camera and CANOPON software. Damage rate was calculated as the number of plants damaged by sparrows/total number of plants $(n=20$ in each study plot).

rate increased with increasing canopy openness (GLMM, $p=0.001)$, indicating that dense weed thickets reduce damage. The odds ratio of this statistical model estimated that an increase in canopy openness of $20 \%$ would increase damage by 2.08 -fold. I hypothesized that reduced visibility at the periphery of paddy fields is effective in reducing habitat quality for birds and that lowered habitat quality reduces rice damage. My results supported this hypothesis. Low visibility induces a higher scanning rate and a higher risk of predation. In addition, dense weed thickets might completely inhibit predator detection despite frequent scanning [6] and, consequently, tree sparrows should prefer open habitats with high visibility. Dense weed thickets represent the opposite of this preferred habitat. As a result, decreased weeding effort decreases damage and is a convenient means of damage management because of its low cost and low labor intensiveness.

Thick weed thickets decrease visibility but might also provide safe cover for birds, as cover decreases detection by predators [6]. Thus, thick weed thickets decrease the visual detectability of both sparrows and predators. However, my results indicate that tree sparrows saw weed thickets as risky habitats, rather than safe cover.

Tree sparrows damage rice from initial ear emergence to the time of grain-filling, with the greatest risk during the latter period [8]. Therefore, my damage estimate was similar in each paddy field. Although I assume that sites with the same ID had similar risk (i.e., autocorrelation), I addressed this problem using random intercepts (GLMM). High risk paddy fields (e.g., fields in the grain-filling period) had large intercepts, and low risk paddy fields had small intercepts. The difference in damage risk between high and low sparrow 
density was also handled using random intercepts. Thus, the GLMM was well suited for this study.

\section{Conclusions}

To reduce rice damage caused by tree sparrows, weed management efforts should be reduced. The effects of weed management on damage were sizeable: a $20 \%$ increase in canopy openness resulted in a 2.08-fold increase in damage. There are no viable alternative countermeasures for tree sparrow damage, but my proposed technique is effective and inexpensive and requires little labor. The only existing alternative is netting, but this measure is both expensive and labor intensive $[17,18]$. Thus, as a first step in damage management, my technique shows real promise.

\section{Disclosure}

This study did not use animals directly.

\section{Conflict of Interests}

The author declares that there is no conflict of interests regarding the publication of this paper.

\section{Acknowledgments}

The author thanks Hisato Takeuchi for assistance with fieldwork and Travis Carlton Tewes and Hiromi Tewes for their help in editing the paper.

\section{References}

[1] S. L. Lima, "Distance to cover, visual obstructions, and vigilance in house sparrows," Behaviour, vol. 102, no. 3-4, pp. 231-238, 1987.

[2] G. Beauchamp, Animal Vigilance: Monitoring Predators and Competitors, Academic Press, London, UK, 2015.

[3] M. A. Elgar, "House sparrows establish foraging flocks by giving chirrup calls if the resources are divisible," Animal Behaviour, vol. 34, no. 1, pp. 169-174, 1986.

[4] M. A. Elgar, "Food intake rate and resource availability: flocking decisions in house sparrows," Animal Behaviour, vol. 35, no. 4, pp. 1168-1176, 1987.

[5] H. Poysa, "Feeding-vigilance trade-off in the teal (Anas crecca): effects of feeding method and predation risk," Behaviour, vol. 103, no. 1-3, pp. 108-122, 1987.

[6] M. J. Whittingham and K. L. Evans, "The effects of habitat structure on predation risk of birds in agricultural landscapes," Ibis, vol. 146, no. 2, pp. 210-220, 2004.

[7] J. Lazarus and M. Symonds, "Contrasting effects of protective and obstructive cover on avian vigilance," Animal Behaviour, vol. 43, no. 3, pp. 519-521, 1992.

[8] S. Kasahara, G. Morimoto, Y. Yamaguchi, O. K. Mikami, and $\mathrm{K}$. Ueda, "Effects of rice ripeness and distance between rice fields and residential areas on foraging habitat selection by the Eurasian Tree sparrow Passer montanus," Japanese Journal of Ornithology, vol. 62, no. 1, pp. 24-30, 2013 (Japanese).
[9] M. Sano, "Structure of population range in Passer montanus," Journal of the Yamashina Institute for Ornithology, vol. 7, no. 1, pp. 73-86, 1973.

[10] T. Honda, "Line color affects the collision risk and deterrence of crows," Journal of Ethology, vol. 30, no. 1, pp. 11-14, 2012.

[11] R. J. Johnson, P. H. Cole, and W. W. Stroup, "Starling response to three auditory stimuli," Journal of Wildlife Management, vol. 49, no. 3, pp. 620-625, 1985.

[12] M. Bomford and P. H. O'Brien, "Sonic deterrents in animal damage control: a review of device tests and effectiveness," Wildlife Society Bulletin, vol. 18, no. 4, pp. 411-422, 1990.

[13] B. F. Blackwell, G. E. Bernhardt, and R. A. Dolbeer, "Lasers as nonlethal avian repellents," Journal of Wildife Management, vol. 66, no. 1, pp. 250-258, 2002.

[14] W. P. Gorenzel, B. F. Blackwell, G. D. Simmons, T. P. Salmon, and R. A. Dolbeer, "Evaluation of lasers to disperse American crows, Corvus brachyrhynchos, from urban night roosts," International Journal of Pest Management, vol. 48, no. 4, pp. 327-331, 2002.

[15] R. A. Dolbeer, M. A. Link, and P. P. Woronecki, "Naphthalene shows no repellency for starlings," Wildlife Society Bulletin, vol. 16, pp. 62-64, 1988.

[16] J. Tracey, M. Bomford, Q. Hart, G. Saunders, and R. Sinclair, Managing Bird Damage to Fruit and Other Horticultural Crops, Bureau of Rural Sciences, Canberra, Australia, 2007.

[17] M. R. Conover, "Behavioral techniques to reduce bird damage to blueberries: metiocarb and a hawk-kite predator model," Wildlife Society Bulletin, vol. 10, pp. 211-216, 1982.

[18] K. McNamara, P. O'Kiely, J. Whelan, P. D. Forristal, and J. J. Lenehan, "Preventing bird damage to wrapped baled silage during short- and long-term storage," Wildlife Society Bulletin, vol. 30, no. 3, pp. 809-815, 2002.

[19] M. Fujioka and K. Nakamura, Countermeasure against Crop Damage by Birds, Ienohikari, Tokyo, Japan, 2000 (Japanese).

[20] R Development Core Team, R: A Language and Environment for Statistical Computing, R Foundation for Statistical Computing, Vienna, Austria, 2012, http://www.R-project.org/. 

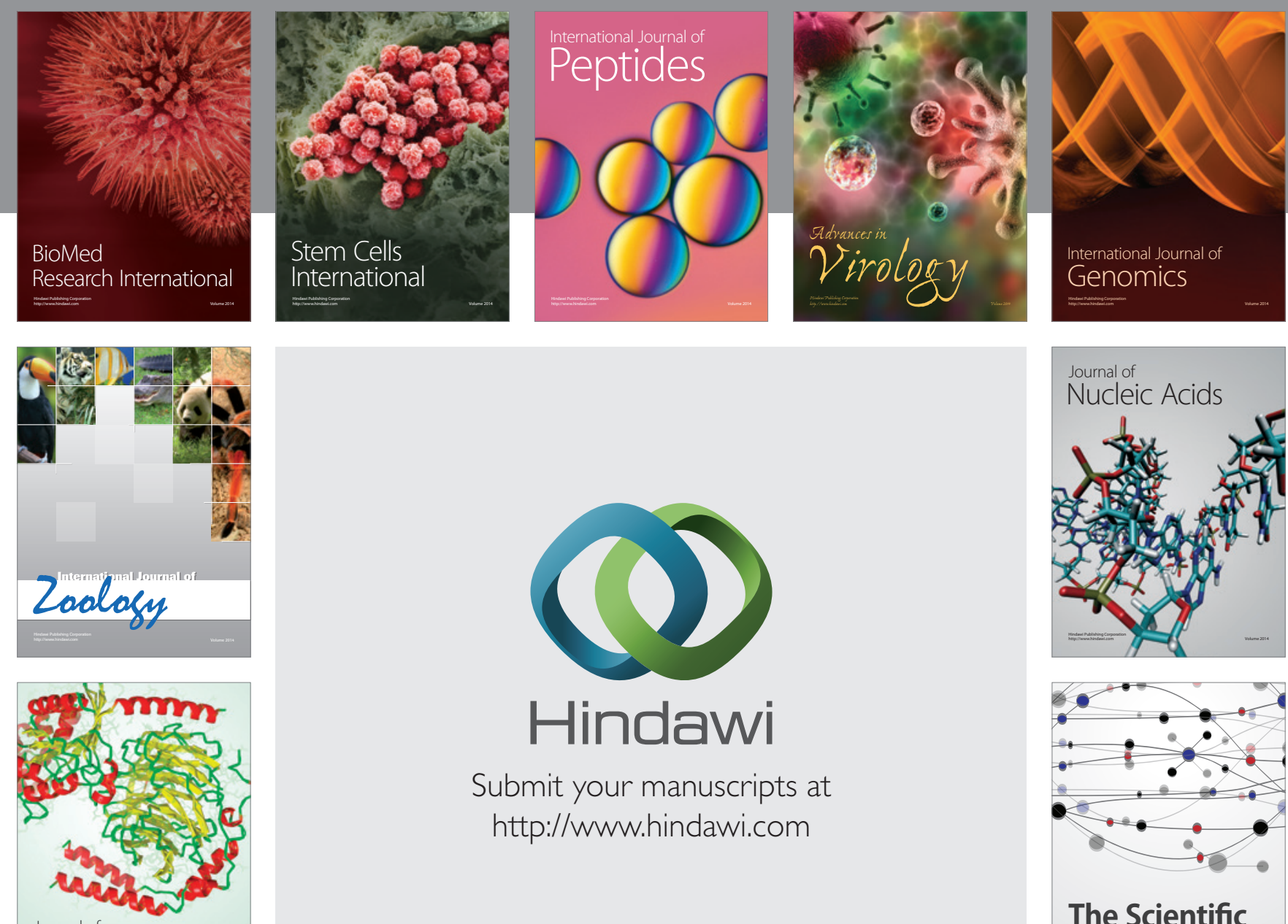

Submit your manuscripts at

http://www.hindawi.com

Journal of
Signal Transduction
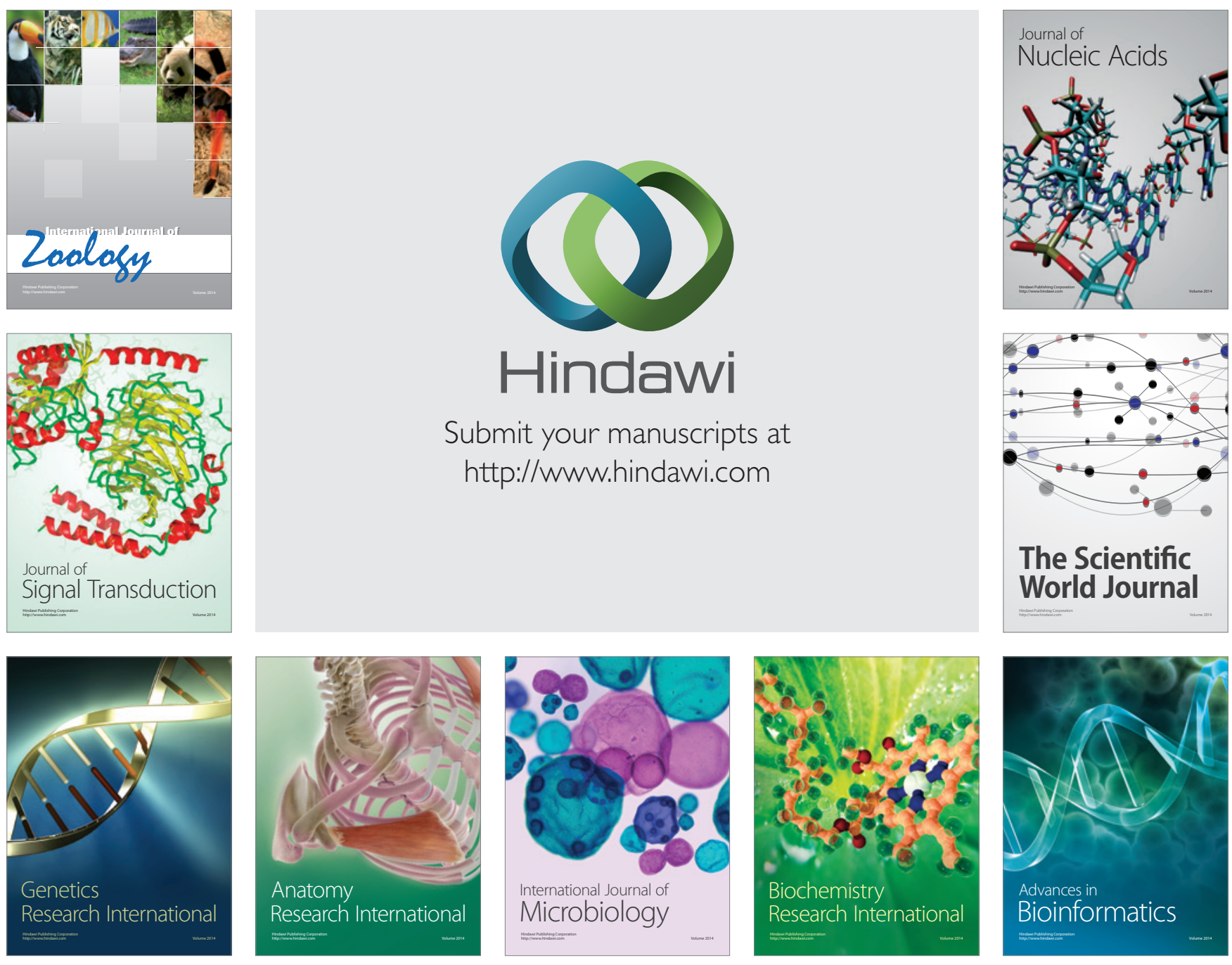

The Scientific World Journal
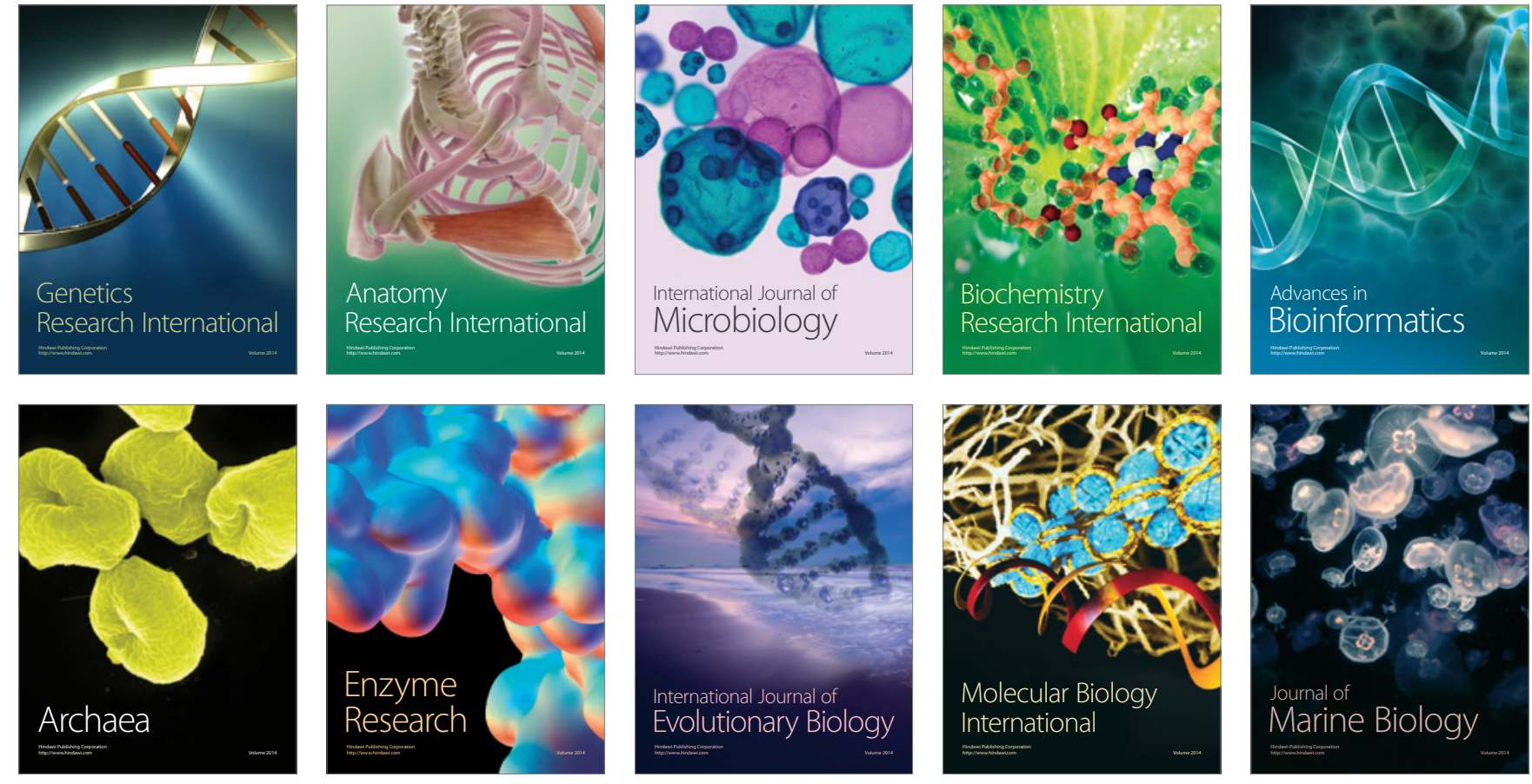